\title{
PRODUÇÃO DE MUDAS DE CAJUEIRO (ANACARDIUM OCCIDENTALE) COM USO DE ESTERCO BOVINO CURTIDO E BIOFERTILIZANTE
}

\author{
AUTOR: FERNANDO SILVA DOS SANTOS \\ CO-AUTOR/ORIENTADOR: ABILIO JOSE PROCOPIO QUEIROZ
}

\begin{abstract}
Resumo: As atividades agrícolas são responsáveis por diversas alterações ambientais, e o uso dos produtos sintetizados no manejo das culturas de interesse agrícola comercial é uma das causas, o que acarreta diversos impactos negativos em suas áreas de influência. Diante do exposto, este projeto teve como objetivo produzir mudas de duas espécies frutíferas - Carica papaya e Anacardium occidentale - com uso de esterco bovino curtido ou não curtido e biofertilizante. Foram desenvolvidos 18 tratamentos e 4 repetições, variando de 0 a $100 \%$ as concentrações dos elementos dos substratos e considerando o uso ou não do biofertilizante, definido em delineamento inteiramente casualizado. Todos resultados foram tratados estatisticamente, sendo submetidos à análise de variância, utilizando o teste de Tukey a 5\% de probabilidade para comparação das médias. Para a cultura do cajueiro o tratamento 4 ( $75 \%$ de solo e $25 \%$ de esterco bovino não curtido) foi o responsável pelo melhor conjunto de variáveis analisadas. Vale ressaltar que os maiores valores para a variável massa seca da raiz pode ser um indicativo de necessidade por nutrientes, que favoreceu a expansão do sistema radicular para atender a uma provável estabilidade desses elementos químicos em seu sistema. Os valores para as variáveis estudadas foram compatíveis e em algumas situações até superiores em relação a outros experimentos conduzidos com a mesma cultura. A produção de mudas de cajueiro sem o uso de produtos sintéticos é uma possibilidade viável, evitando dessa forma os impactos ambientais negativos e os custos financeiros associados comumente observados em um modelo de produção agrícola convencional.
\end{abstract}

Palavras-chave: Cultura agrícola, fertirrigação, orgânicos. 